\title{
Exposure to Secondhand Tobacco Smoke Enhances Respiratory Symptoms and Responses to Animals in 8,819 Children in Kindergarten: Results from 25 Districts in Northeast China
}

\author{
Guang-Hui Dong a, b Wan-Hui Ren ${ }^{d}$ Da Wang $^{a}$ Zong-Hua Yang ${ }^{a}$ \\ Peng-Fei Zhang ${ }^{a}$ Ya-Dong Zhao ${ }^{c}$ Qin-Cheng He ${ }^{b}$ \\ Departments of ${ }^{a}$ Biostatistics and Epidemiology and ${ }^{b}$ Occupational and Environmental Medicine, \\ School of Public Health, and 'Institute of Respiratory Diseases, First Affiliated Hospital, China Medical University, and \\ ${ }^{\mathrm{d}}$ Shenyang Environmental Monitoring Center, Shenyang, PR China
}

\section{Key Words}

Asthma • Animals • Environmental tobacco smoke •

Children

\begin{abstract}
Background: Experimental data suggest that asthma exacerbation by allergens is enhanced by exposure to environmental tobacco smoke (ETS); however, there is little supporting epidemiologic evidence. To our knowledge, few studies have assessed respiratory symptoms and allergies in this context. Objectives: To evaluate whether the association of exposure to animals (indicators of allergen and endotoxin exposure) with asthma-related symptoms is modified by ETS exposure in Chinese children. Methods: A cross-sectional study of 8,819 children in kindergarten was conducted in 25 districts in northern China. Information on respiratory health and exposure to indoor allergens was obtained using a standard questionnaire from the American Thoracic Society. $\boldsymbol{R} \boldsymbol{e}$ sults: Among the children with ETS exposure in utero, the effects of exposure to animals were significant with respect to persistent cough [adjusted odds ratio (OR) 1.83; 95\% confidence interval $(\mathrm{Cl})$ 1.12-2.99] and persistent phlegm (adjusted OR 2.40; 95\% Cl 1.28-4.54). The combined effect of in
\end{abstract}

utero ETS exposure and animal exposure on doctor-diagnosed asthma was approximately as expected on the basis of their independent effects on an additive scale. There was no interaction between animal exposure and ETS exposure in the first 2 years of life or current ETS exposure. Conclusions: This study provides evidence that animal and ETS exposure increases the risk of asthma-related symptoms in children in kindergarten. ETS exposure in utero did modify the effect of animal exposure on persistent phlegm and persistent cough but not on doctor-diagnosed asthma among children.

Copyright $\odot 2010$ S. Karger AG, Basel

\section{Introduction}

Evidence shows that environmental tobacco smoke (ETS) as well as indoor allergens such as those from dogs, cats, and cockroaches all exacerbate asthma [1-4]. In addition, increasing experimental evidence shows that ETS exposure enhances the effect of the inhaled allergen on the physiologic response in the lungs of asthmatics and experimental animals [5-11]. However, there have been few epidemiologic evaluations of the effect of coexposure

\section{KARGER}

Fax +4161306 1234

E-Mail karger@karger.ch

www.karger.com (c) 2010 S. Karger AG, Basel

$0025-7931 / 11 / 0813-0179 \$ 38.00 / 0$

Accessible online at:

www.karger.com/res
Guang-Hui Dong and Qin-Cheng He, Department of Biostatistics and Epidemiology

School of Public Health, China Medical University

92 North 2nd, Heping Districts, Shenyang 110001 (PR China)

Tel. +86242325 6666, ext. 5394, Fax +86242326 5492

E-Mail ghdong@mail.cmu.edu.cn and qche@mail.cmu.edu.cn 
to ETS and endotoxins or exposure to indoor allergens on asthma symptoms and asthma-related symptoms.

We hypothesized that exposure to ETS enhances the symptomatic response to exposure to indoor allergens among children. The aim of our study was to test this hypothesis in Chinese children in kindergarten. Animal ownership was used as a marker of indoor exposure to allergens because animal ownership has been shown to be a strong predictor of the concentration of the respective allergen $[3,12]$. Our study was conducted in a total of 8,819 children from 50 kindergartens in 25 districts in northeast China during 2009. We collected lifetime ETS exposure (including ETS exposure during pregnancy, ETS exposure in the first 2 years of life, and current ETS exposure) and animal exposure histories, as well as parental reports of respiratory symptoms and diseases (including persistent cough, persistent phlegm, doctor-diagnosed asthma, current asthma, current wheeze, and allergic rhinitis), at enrollment to examine the relationships between childhood coexposure to ETS and animals and respiratory symptoms and diseases.

\section{Methods}

\section{Participants and Study Procedure}

The procedures followed were in accordance with the Ethical Standards of the Responsible Committee on Human Experimentation of China Medical University, and this study was approved by the ethics committee of China Medical University. Children $(\mathrm{n}=9,649)$ aged 2-6 years and in kindergarten were surveyed from 25 districts in 7 cities in Liaoning Province, China; 8,819 children actually responded, and the response rate was $91.4 \%$. Liaoning Province is located in Northeast China and includes 14 cities. From April 2009 to October 2009, seven cities (Shenyang, Dalian, Anshan, Fushun, Benxi, Liaoyang, and Yingkou) were randomly selected from Liaoning Province. There are 5 inner-city districts in Shenyang city, 4 in Dalian city, 4 in Fushun city, and 3 in Anshan city, Benxi city, Liaoyang city, and Yingkou city, respectively. Two kindergartens were randomly picked from each district of the selected cities. The resulting 50 kindergartens were included. Local study staff informed participants about the survey at the participating schools. Teachers were given verbal and written instructions, questionnaires with envelopes, and forms to record questionnaire distribution and collection. After obtaining written parental consent, parents were invited to a parents' night with the attendance of study staff where teachers explained the study and the conditions of consent. Teachers were instructed not to force parents to fill out the questionnaire as compliance was strictly voluntary. Parents who wished to participate completed the questionnaire at home and returned it (via the child) to the teacher in an envelope. Endorsed consent forms were obtained from the parents or guardians of the subjects before their participation in the study.

\section{Questionnaire Data}

We assessed children's respiratory health, as well as potential risk factors such as exposure to indoor allergens, using a questionnaire. We included respiratory health-related questions from the American Thoracic Society's (ATS) Epidemiologic Standardization Project questionnaire, which had been proved to be valid in some studies [2, 13-16]. This questionnaire had already been translated into Chinese for previous studies in other Chinese cities $[2,13,15,16]$.

Children's respiratory conditions were determined from questionnaire responses and were defined as follows: (a) doctor-diagnosed asthma: a 'yes' answer to the question 'Has a doctor ever diagnosed asthma in this child?'; (b) current asthma: under the condition that the child has been diagnosed asthma, a 'yes' answer to the question 'Has this child been in a paroxysm of asthma in the last 2 years?' or a 'yes' answer to the question 'Does this child take medicine or treatment for asthma or asthmatic bronchitis?'; (c) current wheeze: a 'yes' answer to the question 'Does this child's chest ever sound wheezy or whistling, including times when he or she had a cold?' and a 'yes' answer to the question 'Has this child had 2 or more such episodes in the last 12 months?'; (d) persistent cough: the answer to several cough-related questions which indicate that the studied child had cough on most days (4 or more days per week) for at least 3 months a year either with or without cold during the last 12 months; (e) persistent phlegm: the answer to several phlegm-related questions which indicate that the studied child had been seen to be congested or had had a productive cough on most days (4 or more days per week) for at least 3 months a year either with or without cold during the last 12 months, and (f) allergic rhinitis: a 'yes' answer to the question 'Has a doctor ever diagnosed allergic rhinitis in this child?'. In order to detect the seasonal variation of these asthmatic symptoms, we also asked 'In which month did this asthmatic symptom usually occur?'.

Current exposure to animals was characterized by questions defining the type and number of animals in the child's household during past 12 months. We created a categorical variable indicating whether the child was exposed to dogs, cats, farm animals, or other types of animals. We included chickens, ducks, cows, and pigs in the farm animal category. Children who did not have any animals were assigned to the reference category. We also asked whether the mother had been exposed to animals during pregnancy with this child and whether this child had been exposed to animals during the first year of life. Reported ETS exposure was classified 3 different ways: current household exposure, any passive smoking during the first 2 years of the child's life, and any passive smoking during maternal pregnancy with this child. Information regarding smoking by visitors or guests was not requested. The current number of household smokers and the current number of cigarettes smoked inside the house per day were recorded. The following 3 categories were defined: none, 1-10 cigarettes smoked per day, and $>10$ cigarettes smoked per day. Parental atopy was defined as a history of maternal or paternal asthma, allergic rhinitis, hay fever, allergic eczema, or allergic conjunctivitis. Information on this history was obtained in the questionnaire.

\section{Statistical Analysis}

We calculated adjusted odds ratios (OR) with 95\% confidence intervals (CI) for each of the 5 outcome measures using unconditional logistic regression (PROC LOGISTIC in SAS System for 
Windows, version 8.12; SAS Institute, Inc., Cary, N.C., USA). We studied the relation between a history of asthma and asthma-related symptoms and parental atopy and current exposure to individual animals or any animal combined. We also studied the independent and joint effects of parental atopic diseases and animal exposure by comparing the risk of asthma in 4 exposure categories: (1) no ETS exposure and no animal exposure (reference category); (2) animal exposure but no ETS exposure; (3) ETS exposure but no animal exposure, and (4) both ETS and animal exposure. We calculated ORs contrasting each of the 3 exposure categories with the reference category. Estimates for the independent effects of ETS and animal exposure and their joint effect were derived from the same logistic regression model, adjusting for the following covariates assessed as potential confounders: age, gender, breast feeding, use of domestic cooking and heating fuels, parental atopy, area per person, household decorations, and parental education.

\section{Results}

The characteristics of the study population are presented in table 1 . The mean age of the children was 4.7 years (SD 1.2 years; range: $2.2-6.7$ ). The prevalence of doctor-diagnosed asthma, current asthma, current wheeze, persistent cough, and persistent phlegm was 7.9, $3.5,11.0,13.3,5.7$, and $2.8 \%$, respectively (table 1 ).

Table 2 presents the risk of doctor-diagnosed asthma and asthma-related symptoms in relation to ETS exposure and the presence of animal exposure in the home among children in kindergarten. After adjusting for a set of other covariates, current ETS exposure was significantly associated with doctor-diagnosed asthma, current wheeze, persistent cough, and persistent phlegm among children, and the associations between current ETS exposure and the respiratory health of the children increased in strength with the number of cigarettes smoked inside the house per day. Among subjects who gave information about ETS exposure in the first 2 years of life and during pregnancy, these exposures were strongly associated with respiratory symptoms.

In the children, animal exposure during pregnancy was positively associated with current wheeze (OR 1.80; 95\% CI 1.17-2.77) and allergic rhinitis (OR 2.52; 95\% CI 1.43-4.44). Exposure to animals in the first year of life was also related to a significantly higher prevalence of doctor-diagnosed asthma (OR 1.80; 95\% CI 1.19-2.73), current asthma (OR 2.39; 95\% CI 1.41-4.08), and asthmarelated symptoms in these children. Current animal exposure was positively associated with persistent cough (OR 1.20; 95\% CI 1.01-1.42) and persistent phlegm (OR 1.69 ; 95\% CI 1.34-2.13) in the past 12 months, but not
Table 1. Characteristics of the study population of children $(\mathrm{n}=$ 8,819) from 50 kindergartens in Liaoning Province, China

\begin{tabular}{|c|c|}
\hline Characteristics & Children, $\mathrm{n}(\%)$ \\
\hline \multicolumn{2}{|l|}{ Gender } \\
\hline Male & $4,470(50.7)$ \\
\hline Female & $4,349(49.3)$ \\
\hline \multicolumn{2}{|l|}{ Asthma and asthma-related symptoms } \\
\hline Doctor-diagnosed asthma & $697(7.9)$ \\
\hline Current asthma & $312(3.5)$ \\
\hline Current wheeze & $971(11.0)$ \\
\hline Persistent cough & $1,173(13.3)$ \\
\hline Persistent phlegm & $500(5.7)$ \\
\hline Allergic rhinitis & $243(2.8)$ \\
\hline Parental history of atopic diseases & $624(7.1)$ \\
\hline \multicolumn{2}{|l|}{ Environmental factors } \\
\hline Exposure to animals during pregnancy & $415(4.7)$ \\
\hline Exposure to animals in the first year of life & $450(5.1)$ \\
\hline \multicolumn{2}{|l|}{ Current exposure to animals } \\
\hline No & $7,224(81.9)$ \\
\hline Yes & $1,595(18.1)$ \\
\hline \multicolumn{2}{|l|}{ Number of animals } \\
\hline 1 & $1,335(15.1)$ \\
\hline$\geq 2$ & $260(3.0)$ \\
\hline Dogs & $422(5.5)$ \\
\hline Cats & $374(4.9)$ \\
\hline Birds & $346(4.6)$ \\
\hline Farm animals & $309(3.5)$ \\
\hline Other animals & $381(5.0)$ \\
\hline Current ETS exposure & $4,389(49.8)$ \\
\hline ETS exposure in the first 2 years of life & $1,923(21.8)$ \\
\hline ETS exposure during pregnancy & $534(6.1)$ \\
\hline \multicolumn{2}{|c|}{ Exposure to cigarettes (number of cigarettes smoked per day) } \\
\hline 0 & $4,430(50.2)$ \\
\hline $1-10$ & $3,376(38.3)$ \\
\hline$>10$ & $1,013(11.5)$ \\
\hline Household decoration in the last 2 years & $3,225(36.6)$ \\
\hline Breast feeding & $7,770(88.1)$ \\
\hline Number of rooms $<3$ & $4,383(49.7)$ \\
\hline Use of coal in the home & $388(4.4)$ \\
\hline \multicolumn{2}{|l|}{ Parents' level of education is beyond } \\
\hline higher school & $1,269(14.4)$ \\
\hline
\end{tabular}

with doctor-diagnosed asthma (OR 1.17; 95\% CI 0.951.45). In addition, subjects who had 2 or more animals were more likely to report persistent phlegm than were those who had only 1 animal. When analyzing according to the type of animal(s), it was found that doctor-diagnosed asthma was only strongly related to cat exposure (OR 1.66; 95\% CI 1.19-2.32).

Table 3 shows the joint effect of ETS exposure and animal exposure among children in kindergarten. In children without animal exposure, ETS exposure in utero 
Table 2. Adjusted ORs (95\% CI) of asthma-related symptoms and doctor-diagnosed asthma in relation to parental atopy and current animal exposure in children in kindergarten $(\mathrm{n}=8,819)$

\begin{tabular}{|c|c|c|c|c|c|c|}
\hline Characteristics & $\begin{array}{l}\text { Persistent } \\
\text { cough }\end{array}$ & $\begin{array}{l}\text { Persistent } \\
\text { phlegm }\end{array}$ & $\begin{array}{l}\text { Doctor-diagnosed } \\
\text { asthma }\end{array}$ & $\begin{array}{l}\text { Current } \\
\text { asthma }\end{array}$ & $\begin{array}{l}\text { Current } \\
\text { wheeze }\end{array}$ & $\begin{array}{l}\text { Allergic } \\
\text { rhinitis }\end{array}$ \\
\hline \multicolumn{7}{|l|}{ ETS exposure } \\
\hline In utero (ref.: no) & $1.33(1.05,1.70)$ & $1.44(1.04,2.00)$ & $1.57(1.19,2.08)$ & $2.01(1.39,2.90)$ & $1.60(1.25,2.05)$ & $1.50(0.98,2.30)$ \\
\hline In the first 2 years of life (ref.: no) & $1.48(1.29,1.71)$ & $1.52(1.24,1.86)$ & $1.62(1.36,1.92)$ & $1.25(0.97,1.62)$ & $1.49(1.28,1.73)$ & $1.05(0.77,1.43)$ \\
\hline Current (ref.: no) & $1.40(1.23,1.59)$ & $1.51(1.25,1.82)$ & $1.30(1.11,1.53)$ & $1.18(0.94,1.48)$ & $1.35(1.17,1.54)$ & $1.01(0.78,1.31)$ \\
\hline \multicolumn{7}{|c|}{ Exposure to cigarettes (number of cigarettes smoked per day) ${ }^{1}$} \\
\hline $1-10$ & $1.32(1.15,1.51)$ & $1.48(1.21,1.80)$ & $1.25(1.05,1.48)$ & $1.18(0.92,1.50)$ & $1.28(1.10,1.48)$ & $0.99(0.75,1.31)$ \\
\hline$>10$ & $1.69(1.40,2.04)$ & $1.63(1.23,2.14)$ & $1.48(1.17,1.87)$ & $1.19(0.83,1.70)$ & $1.59(1.30,1.95)$ & $1.08(0.72,1.61)$ \\
\hline \multicolumn{7}{|l|}{ Animal exposure } \\
\hline In utero (ref.: no) & $1.00(0.64,1.58)$ & $2.10(1.26,3.50)$ & $1.23(0.74,2.06)$ & $1.82(0.97,3.44)$ & $1.80(1.17,2.77)$ & $2.52(1.43,4.44)$ \\
\hline In the 1st year (ref.: no) & $1.04(0.70,1.54)$ & $1.65(1.01,2.70)$ & $1.80(1.19,2.73)$ & $2.39(1.41,4.08)$ & $2.19(1.52,3.17)$ & $1.55(0.85,2.84)$ \\
\hline Current (ref.: no) & $1.20(1.01,1.42)$ & $1.69(1.34,2.13)$ & $1.17(0.95,1.45)$ & $0.96(0.69,1.34)$ & $1.06(0.87,1.28)$ & $1.51(1.09,2.10)$ \\
\hline \multicolumn{7}{|l|}{ Number of animals ${ }^{2}$} \\
\hline 1 & $1.23(1.03,1.47)$ & $1.66(1.30,2.12)$ & $1.15(0.92,1.44)$ & $1.04(0.74,1.47)$ & $1.05(0.86,1.29)$ & $1.60(1.13,2.25)$ \\
\hline$\geq 2$ & $1.04(0.72,1.51)$ & $1.83(1.17,2.86)$ & $1.27(0.84,1.93)$ & $0.59(0.26,1.36)$ & $1.10(0.73,1.64)$ & $1.13(0.57,2.22)$ \\
\hline \multicolumn{7}{|l|}{ Types of animals ${ }^{2}$} \\
\hline Cats & $1.52(1.14,2.03)$ & $2.57(1.80,3.68)$ & $1.66(1.19,2.32)$ & $1.48(0.90,2.42)$ & $1.05(0.74,1.49)$ & $1.88(1.15,3.09)$ \\
\hline Dogs & $0.94(0.69,1.29)$ & $1.50(1.01,2.26)$ & $1.07(0.73,1.55)$ & $0.62(0.32,1.23)$ & $1.09(0.78,1.52)$ & $1.34(0.72,2.47)$ \\
\hline Birds & $1.01(0.72,1.40)$ & $1.26(0.79,2.02)$ & $0.98(0.66,1.48)$ & $0.77(0.40,1.48)$ & $1.02(0.71,1.46)$ & $1.12(0.59,2.13)$ \\
\hline Farm animals & $1.29(0.87,1.91)$ & $2.21(1.37,3.58)$ & $1.06(0.63,1.79)$ & $0.66(0.26,1.66)$ & $1.02(0.64,1.63)$ & $1.97(0.97,3.99)$ \\
\hline Other animals & $1.18(0.88,1.60)$ & $1.57(1.04,2.35)$ & $1.16(0.80,1.68)$ & $0.74(0.38,1.42)$ & $0.88(0.61,1.27)$ & $1.42(0.80,2.51)$ \\
\hline
\end{tabular}

ORs are adjusted for age, gender, breast feeding, use of domestic cooking and heating fuels, ETS, area per person, household decorations, parental education, parental atopy, and animal exposure variables. ref. = Reference.

${ }^{1}$ ORs are computed in relation to subjects with no ETS exposure. ${ }^{2}$ ORs are computed in relation to subjects with no exposure to animals.

Table 3. Adjusted ORs (95\% CI) of asthma-related symptoms and doctor-diagnosed asthma in relation to the joint effect of coexposure to ETS and animals in children in kindergarten

\begin{tabular}{|c|c|c|c|c|c|c|}
\hline Characteristics & $\begin{array}{l}\text { Persistent } \\
\text { cough }\end{array}$ & $\begin{array}{l}\text { Persistent } \\
\text { phlegm }\end{array}$ & $\begin{array}{l}\text { Doctor-diagnosed } \\
\text { asthma }\end{array}$ & $\begin{array}{l}\text { Current } \\
\text { asthma }\end{array}$ & $\begin{array}{l}\text { Current } \\
\text { wheeze }\end{array}$ & $\begin{array}{l}\text { Allergic } \\
\text { rhinitis }\end{array}$ \\
\hline \multicolumn{7}{|c|}{ ETS exposure in utero } \\
\hline Children $^{3}$ & $1.20(0.90,1.60)$ & $1.45(1.00,2.01)$ & $1.59(1.15,2.21)$ & $2.08(1.38,3.14)$ & $1.59(1.20,2.11)$ & $1.56(0.92,2.63)$ \\
\hline Children $^{4}$ & $1.21(1.01,1.44)$ & $1.70(1.35,2.18)$ & $1.19(0.96,1.49)$ & $0.96(0.68,1.36)$ & $1.08(0.88,1.32)$ & $1.46(1.03,2.06)$ \\
\hline Children $^{5}$ & $2.30(1.48,3.57)$ & $3.36(1.94,5.82)$ & $1.94(1.15,3.29)$ & $1.88(0.87,4.06)$ & $1.66(0.99,2.78)$ & $2.21(1.04,4.69)$ \\
\hline Children $^{2}$ (ref.) ${ }^{1}$ & 1.00 & 1.00 & 1.00 & 1.00 & 1.00 & 1.00 \\
\hline Children $^{3}$ & $1.50(1.28,1.75)$ & $1.66(1.32,2.10)$ & $1.67(1.37,2.03)$ & $1.31(0.99,1.75)$ & $1.42(1.20,1.68)$ & $1.01(0.69,1.46)$ \\
\hline Children $^{4}$ & $1.26(1.03,1.54)$ & $1.97(1.50,2.59)$ & $1.22(0.95,1.58)$ & $1.02(0.69,1.49)$ & $0.95(0.75,1.21)$ & $1.45(0.99,2.12)$ \\
\hline Children $^{5}$ & $1.73(1.32,2.28)$ & $2.44(1.68,3.53)$ & $1.77(1.27,2.48)$ & $0.95(0.53,1.68)$ & $1.72(1.27,2.31)$ & $1.52(0.89,2.61)$ \\
\hline \multicolumn{7}{|c|}{ Current ETS exposure } \\
\hline \multicolumn{7}{|c|}{$\begin{array}{l}\text { ORs are adjusted for age, gender, breast feeding, use of domes- } \\
\text { tic cooking and heating fuels, parental atopy, area per person, } \\
\text { house decorations, parents' education. ref = Reference. } \\
{ }^{1} \text { ORs are computed in relation to children with no ETS and no } \\
\text { animal exposure (reference category). }\end{array}$} \\
\hline
\end{tabular}


alone significantly increased the risk of doctor diagnosed asthma, with an adjusted OR of 1.59 (95\% CI 1.15-2.21) which corresponds to a $59 \%$ excess risk. The effect of animal exposure was not significant in children with no ETS exposure in utero, with an adjusted OR of 1.19 (95\% CI, 0.96-1.49) which corresponds to a $19 \%$ excess risk. The adjusted OR of doctor-diagnosed asthma was 1.94 (95\% CI 1.15-3.29), which corresponds to a $94 \%$ excess risk, in children with both ETS exposure in utero and animal exposure compared with subjects in the reference category. The combined effect of in utero ETS exposure and animal exposure was approximately as expected on the basis of their independent effects on an additive scale. Also, there was no interaction in terms of ETS exposure in the first 2 years of life or current ETS exposure and animal exposure at home $(\mathrm{p}>0.05)$. The combined effect of these 2 factors was approximately as expected on the basis of their independent effects on the additive scale.

Interestingly, we found an effect of ETS exposure in utero and animal exposure on the risk of persistent phlegm and persistent cough. In children without animal exposure, ETS exposure in utero corresponds to a $45 \%$ excess risk of persistent phlegm, and in children with no ETS exposure in utero, animal exposure results in a 70\% excess risk. However, compared with children in the reference category, there was a $236 \%$ (adjusted OR 3.36) excess risk of persistent phlegm in subjects with both ETS exposure in utero and animal exposure, which was approximately twice their independent effects on an additive scale. A similar pattern was observed in persistent cough. Among the children with ETS exposure in utero, the effects of exposure to animals were not significant with respect to doctor-diagnosed asthma (adjusted OR 1.39; 95\% CI 0.79-2.48), but they were significant with respect to persistent cough (adjusted OR 1.83; 95\% CI 1.12-2.99) and persistent phlegm (adjusted OR 2.40; 95\% CI 1.28-4.54).

\section{Discussion}

Our results indicate an increased risk of sensitization to animals (indicators of allergen exposure) in children who were exposed to tobacco smoke. The effect seemed to be restricted to ETS exposure in utero, whereas the risk of developing sensitization to animals was not statistically increased among children exposed to ETS in the first 2 years of life or with current ETS exposure. This may be explained by the fact that tobacco smoke exposure seems to act very early, starting already during pregnan-

ETS, Animals, and Respiration Symptoms in Children cy, and a body of evidence shows that the effect of ETS exposure in utero is stronger than postnatal ETS exposure $[17,18]$. A study of 16,000 school-aged Scandinavian children found that ETS exposure in utero was associated with increases in asthma attacks, dry cough, and asthma treatments. In contrast, postnatal ETS exposure was inversely associated with these end points [17]. Also, a recent report published by the UK Royal College of Physicians titled 'Passive smoking and children' includes the latest meta-analyses of childhood secondhand smoke exposure (at various levels - prenatal, postnatal, household, solely maternal, paternal, etc.) on asthma and wheeze. The effects of ETS exposure also vary by age groups and are much stronger in younger age groups, i.e. less than 2 years of age [19]. Furthermore, rodent studies have confirmed that in utero exposure to ETS can be critical to subsequent respiratory and immune system responses. Rats exposed to sidestream smoke for the first 100 days of life displayed no altered lung function or reactivity to methacholine [20]. In contrast, rats exposed continually to sidestream smoke in utero from gestation day 3 through week 10 after their birth demonstrated a $24 \%$ decrease in lung dynamic compliance and a 20 -fold increase in methacholine reactivity compared with rats exposed to smoke only after birth [21]. Also, recent experimental studies have shown that mice exposed in utero to ETS and then to other allergens as adults had exaggerated responses compared with mice not exposed in utero to ETS [9]. However, exposure of adult mice to ETS failed to enhance the immune response to inhaled allergens [22].

Moreover, a study by Kulig et al. [23] showed that, at the age of 3 years, children who were only postnatally exposed to ETS by a smoking mother also had a 2.2-times higher risk of sensitization to allergens than did unexposed children. In contrast, those only postnatally exposed by a smoking father were less sensitized to allergens, including animal allergens (OR 0.5; 95\% CI 0.1-2.6). However, we did not assess the relation between maternal smoking exposure and atopic diseases because the proportion of maternal smoking is still low. In our study, only $48(0.5 \%)$ mothers reported smoking. In Asia, especially in China, women who smoke are considered to be embarrassing and are discriminated against, so the proportion of current female smokers in cities in China is lower compared with western developed countries. In developed countries, especially in English-speaking countries, almost $25 \%$ of women are smokers. Results from the European Community Respiratory Health Survey (ECRHS) showed that the proportion of maternal smoking was over $40 \%$ in Denmark, Iceland, and the 
English-speaking countries, and that the proportion of maternal smoking during pregnancy even reached $27 \%$ in Ireland [24]. This called our attention to the increasing number of younger and female smokers in recent years. Therefore, we should correctly recognize the association of cigarette smoking with children's health and emphasize the importance of education for children's health, which will be useful for the prevention of respiratory diseases in children.

Passive smoke consists of a complex mixture of $>4,000$ different chemicals, and ETS exposure in utero clearly exposes the fetus to carcinogens and other toxins in tobacco that are metabolized into more potent active compounds $[25,26]$. Because the human lung's airway structures are largely complete at birth, it may be that in utero ETS exposure increases the occurrence of asthma-related symptoms by altering critical developmental pathways leading to lower lung function, increased bronchial hyperactivity, and a permanent predisposition to asthma and asthma-related symptoms. Many studies suggest that ETS exposure in utero is associated with deficits in lung function at birth that may persist into young adulthood $[18,27]$. The resultant persistent deficits in small airway function associated with in utero exposure may predispose children to asthma-related symptoms during respiratory infections or other insults that produce inflammation, subsequent bronchial hyperactivity, and airflow obstruction $[28,29]$. Animal studies also suggest that in utero ETS exposure in combination with allergen exposure in mice enhances TH2 responses [11,30], and then the inappropriate persistence of a TH2-dominant response pattern appears to increase the likelihood of allergic sensitization upon sufficient exposure to a variety of common antigens [31]. Because increased and early sensitization to common antigens, in conjunction with decreased lung function and increased bronchial hyperactivity, appears to underlie the pathogenesis of asthma, it is biologically plausible that in utero exposure to ETS increases the occurrence of asthma-related symptoms, especially during the first 6 years of life.

Our study has some limitations. First, this is a crosssectional study and only associations can be concluded from this analysis, so there may be a potential recall bias which may underestimate or overestimate the effects of environmental factors. Second, our outcome measures were based on questionnaire responses alone, the health outcomes were reported and not validated by medical billing information or physician examination, and this study included respiratory symptom prevalence in children, not respiratory symptom incidence; for example, some of the factors that we studied might have affected respiratory symptom prevalence through effects on disease duration rather than disease incidence. Third, the findings of this study are mainly urban northern Chinabased and are therefore not generalizable. However, large epidemiological studies on asthma often rely on reports of the recent symptom history and a physician's diagnosis of asthma because these self-reported measures are cost efficient and practical and their repeatability is generally good [32]. Our findings are of interest, regardless of whether the observed associations were caused by effects related to incidence or duration.

In conclusion, self-reported exposure to animals and ETS contributed independently to asthma-related symptoms in these Chinese children. In utero ETS exposure does modify the effects of animal exposure not on doctor-diagnosed asthma but on persistent phlegm and persistent cough among children in kindergarten. These findings reinforce the need for a public health policy to reduce the exposure of young children to animals and ETS in China. Based on the present study's finding that the number of children with current ETS exposure surpasses $49 \%$, further efforts to call on the Chinese government to intervene to curb smoking by means of antismoking legislations are also warranted.

\section{Acknowledgements}

We would like to thank our subjects for their time and enthusiastic participation. This work was supported by grants from the China Environmental Protection Foundation (CEPF2008123-1-5).

\section{Financial Disclosure and Conflicts of Interest}

The authors have no conflicts of interest to declare.

References

$$
\begin{aligned}
& \text { Broekema M, Ten Hacken NH, Volbeda F, } \\
& \text { Lodewijk ME, Hylkema MN, Postma DS, et } \\
& \text { al: Airway epithelial changes in smoking but } \\
& \text { not in sx-smoking asthmatics. Am J Respir } \\
& \text { Crit Care Med 2009;180:1170-1178. } \\
& \text { Dong GH, Ma YN, Ding HL, Jin J, Cao Y, } \\
& \text { Zhao YD, He QC: Effects of housing charac- } \\
& \text { teristics and home environmental factors on } \\
& \text { respiratory symptoms of 10,784 elementary } \\
& \text { school children from Northeast China. Res- } \\
& \text { piration 2008;76:82-91. }
\end{aligned}
$$


3 Gold DR: Environmental tobacco smoke, indoor allergens, and childhood asthma. Environ Health Perspect 2000;108:643-651.

-4 Ekici M, Ekici A, Akin A, Altinkaya V, Bulcun E: Chronic airway diseases in adult life and childhood infections. Respiration 2008; 75:55-59.

5 Lannerö E, Wickman M, van Hage M, Bergström A, Pershagen G, Nordvall L: Exposure to environmental tobacco smoke and sensitisation in children. Thorax 2008;63:172 176.

-6 Min MG, Song DJ, Miller M, Cho JY, McElwain S, Ferguson P, et al: Coexposure to environmental tobacco smoke increases levels of allergen-induced airway remodeling in mice. J Immunol 2007;178:5321-5328.

-7 Koczulla AR, Noeske S, Herr C, Jörres RA, Römmelt H, Vogelmeier C, Bals R: Acute and chronic effects of smoking on inflammation markers in exhaled breath condensate in current smokers. Respiration 2010;79:61-67.

8 Mouadeb DA, Belafsky PC, Birchall M, Hood C, Konia T, Pinkerton KE: The effects of allergens and tobacco smoke on the laryngeal mucosa of guinea pigs. Otolaryngol Head Neck Surg 2009;140:493-497.

-9 Penn AL, Rouse RL, Horohov DW, Kearney MT, Paulsen DB, Lomax L: In utero exposure to environmental tobacco smoke potentiates adult responses to allergen in BALB/c mice. Environ Health Perspect 2007;115:548-555.

$>10$ Raherison C, Pénard-Morand C, Moreau D, Caillaud D, Charpin D, Kopferschmitt C, et al: Smoking exposure and allergic sensitization in children according to maternal allergies. Ann Allergy Asthma Immunol 2008; 100:351-357.

-11 Seymour BW, Pinkerton KE, Friebertshauser KE, Coffman RL, Gershwin LJ: Secondhand smoke is an adjuvant for T helper-2 responses in a murine model of allergy. J Immunol 1997;159:6169-6175.

12 Arbes SJ Jr, Cohn RD, Yin M, Muilenberg ML, Friedman W, Zeldin DC: Dog allergen (Can f 1) and cat allergen (Fel d 1) in US homes: results from the National Survey of Lead and Allergens in Housing. J Allergy Clin Immunol 2004;114:111-117.
13 Lee YL, Hsiue TR, Lee CH, Su HJ, Guo YL: Home exposures, parental atopy, and occurrence of asthma symptoms in adulthood in southern Taiwan. Chest 2006;129:300-308.

14 Peters JM, Avol E, Gauderman WJ, Linn WS, Navidi W, London SJ, et al: A study of twelve Southern California communities with differing levels and types of air pollution. 2. Effects on pulmonary function. Am J Respir Crit Care Med 1999;159:768-775.

15 Salo PM, Xia J, Johnson A, Li Y, Avol EL, Gong J, et al: Indoor allergens, asthma, and asthma-related symptoms among adolescents in Wuhan, China. Ann Epidemiol 2004; 14:543-550.

16 Zhang JJ, Hu W, Wei F, Wu G, Korn LR, Chapman RS: Children's respiratory morbidity prevalence in relation to air pollution in four Chinese cities. Environ Health Perspect 2002;110:961-967.

17 Forsberg B, Pekkanen J, Clench-Aas J, Martensson MB, Stjernberg N, Bartonova A, et al: Childhood asthma in four regions in Scandinavia: risk factors and avoidance effects. Int J Epidemiol 1997;26:610-619.

18 Gilliland FD, Berhane K, McConnell R, Gauderman WJ, Vora H, Rappaport E, et al: Maternal smoking during pregnancy, environmental tobacco smoke exposure and children lung function. Thorax 2000;55: 271-276.

19 Tobacco Advisory Group of the Royal College of Physicians: Report on passive smoking and children. London, RCP, 2010.

20 Joad JP, Pinkerton KE, Bric JM: Effects of sidestream smoke exposure and age on pulmonary function and airway reactivity in developing rats. Pediatr Pulmonol 1993;16: 281-288.

21 Joad JP, Ji C, Kott KS, Bric JM, Pinkerton KE: In utero and postnatal effects of sidestream cigarette smoke exposure on lung function, hyperresponsiveness, and neuroendocrine cells in rats. Toxicol Appl Pharmacol 1995; 132:63-71.
22 Bowles KS, Horohov DW, Paulsen DB, LeBlanc CJ, Littlefield-Chabaud MA, Ahlert T, et al: Exposure of adult mice to environmental tobacco smoke fails to enhance the immune response to inhaled antigen. Inhal Toxicol 2005; 17:43-51.

23 Kulig M, Luck W, Lau S, Niggemann B, Bergmann R, Klettke U, et al: Effect of pre- and postnatal tobacco smoke exposure on specific sensitization to food and inhalant allergens during the first 3 years of life. Allergy 1999;54:220-228.

24 Svanes C, Omenaas E, Jarvis D, Gulsvik A, Burney P: Parental smoking in childhood and adult obstructive lung disease: results from the European Community Respiratory Health Survey. Thorax 2004;59:295-302.

25 Lofroth G: Environmental tobacco smoke: overview of chemical composition and genotoxic components. Mutat Res 1989;222:7380.

26 Lackmann GM, Salzberger U, Tollner U, Chen M, Carmella SG, Hecht SS: Metabolites of a tobacco-specific carcinogen in urine from new-borns. J Natl Cancer Inst 1999;91: 459-465.

27 Stick SM, Burton PR, Gurrin L, Sly PD, LeSouef PN: Effects of maternal smoking during pregnancy and a family history of asthma on respiratory function in newborn infants. Lancet 1996;348:1060-1064.

28 Cook DG, Strachan DP: Parental smoking, bronchial reactivity and peak flow variability in children. Thorax 1998;53:295-301.

29 Hayes D Jr, Feola DJ, Murphy BS, Shook LA, Ballard HO: Pathogenesis of bronchopulmonary dysplasia. Respiration 2010;79:425436.

30 Moerloose KB, Pauwels RA, Joos GF: Shortterm cigarette smoke exposure enhances allergic airway inflammation in mice. Am J Respir Crit Care Med 2005;172:168-172.

31 Holt PG, Macaubas C, Stumbles PA, Sly D: The role of allergy in the development of asthma. Nature 1999;402:B12-B17.

32 Weissman DN: Epidemiology of asthma: severity matters. Chest 2002;121:6-8. 